13,05

\title{
Однофазные эпитаксиальные слои InFeSb c температурой Кюри выше комнатной
}

\author{
() А.В. Кудрин ${ }^{1,2}$, Ю.А. Данилов ${ }^{1,2}$, В.П. Лесников ${ }^{1}$, О.В. Вихрова ${ }^{1}$, Д.А. Павлов ${ }^{2}$, \\ Ю.В. Усов ${ }^{2}$, Е.А. Питиримова ${ }^{2}$, И.Н. Антонов ${ }^{1}$ \\ ${ }^{1}$ Научно-исследовательский физико-технический институт \\ Нижегородского государственного университета им. Н.И. Лобачевского \\ Нижний Новгород, Россия \\ ${ }^{2}$ Нижегородский государственный университет им. Н.И. Лобачевского, \\ Нижний Новгород, Россия \\ E-mail: kudrin@nifti.unn.ru
}

\begin{abstract}
Методом лазерного распыления в вакууме созданы эпитаксиальные гетероструктуры InFeSb/GaAs. Исследования методом высокоразрешающей просвечивающей электронной микроскопии и микродифракции показали, что слои InFeSb являются монокристаллическими и не содержат нановключений дополнительной фазы. Исследования магнитотранспортных свойств обнаружили, что в структурах наблюдается аномальный эффект Холла и отрицательное магнетосопротивление вплоть до комнатной температуры.
\end{abstract}

Работа выполнена в рамках реализации государственного задания (проект № 8.1751.2017/ПЧ Минобрнауки России), при поддержке РФФИ (гранты № 15-02-07824_a, 16-07-01102_а) и гранта (МК-8221.2016.2) Президента Российской Федерации.

\section{1. Введение}

В последнее время появились работы, показывающие возникновение собственного ферромагнетизма у полупроводниковых матриц $A^{3} B^{5}$, сильно легированных атомами железа, в частности InFeAs [1,2], GaFeSb [3], $\mathrm{AlFeSb}$ [4]. При этом слои GaFeSb демонстрируют ферромагнетизм, проявляющийся в магнитотранспортных и магнитооптических свойствах, вплоть до комнатной температуры [3]. Согласно выполненным экспериментальным работам, в матрицы полупроводников InAs, $\mathrm{GaSb}$ и $\mathrm{AlSb}$ можно вводить значительное количество $\mathrm{Fe}$ (до 8\% относительно содержания In для $\mathrm{InFeSb}$, до $25 \%$ относительно содержания $\mathrm{Ga}$ в $\mathrm{GaFeSb}$ и до $10 \%$ относительно содержания $\mathrm{Al}$ в $\mathrm{AlFeSb}$ ) без образования включений второй фазы. Природа ферромагнетизма в таких слоях остается недостаточно понятной. Высказывается предположение, что для узкозонных полупроводников InFeAs и $\mathrm{GaFeSb}$ ферромагнетизм связан с механизмом косвенного обменного взаимодействия, как и в случае легирования марганцем. Однако, в отличие от марганца, электрическая активность Fе в таких материалах остается дискуссионным вопросом. Концентрация носителей заряда в широкозонном полупроводнике $\mathrm{AlFeSb}$ слишком мала для возникновения обменного взаимодействия посредством носителей заряда. В этом случае выдвигается предположение о механизме короткодействующего обменного взаимодействия между близкорасположенными атомами железа. Накопленный объем результатов исследований позволяет предположить, что возникновение ферромагнетизма в системе $A^{3} \mathrm{Fe} B^{5}$ наиболее вероятно для узкозонных полупроводников. Нами показана возможность формирования однофазных эпитаксиальных структур InFeSb/GaAs с температурой Кюри около комнатной.

\section{2. Методика эксперимента}

Слои InFeSb толщиной $\sim 40 \mathrm{~nm}$ были получены на подложках $i$-GaAs методом периодического лазерного распыления в вакууме мишеней InSb и Fe. Содержание Fe характеризовалось технологическим параметром $Y_{\mathrm{Fe}}=t_{\mathrm{Fe}} /\left(t_{\mathrm{InSb}}+t_{\mathrm{Fe}}\right)$, где $t_{\mathrm{Fe}}$ и $t_{\mathrm{InSb}}-$ время распыления мишени $\mathrm{Fe}$ и $\mathrm{InSb}$ соответственно. Величина $Y_{\mathrm{Fe}}$ варьировалась в диапазоне 0.04-0.17. Температура ростового процесса изменялась в диапазоне $30-250^{\circ} \mathrm{C}$. Структурные исследования слоев $\mathrm{InFeSb}$ проводились с помощью просвечивающего электронного микроскопа JEM-2100F и электронографа ЭМР-102. Элементный состав определялся методом энергодисперсионной рентгеновской спектроскопии с использованием детектора X-max Oxford instruments, смонтированного на электронном микроскопе. Спектральные зависимости коэффициента отражения для слоев InFeSb в диапазоне $1.5-4.5 \mathrm{eV}$ были записаны с использованием спектрофотометра Varian Cary 6000i. Транспортные свойства структур исследовались в геометрии вандер Пау на постоянном токе. Магнитополевые зависимости сопротивления Холла и слоевого сопротивления были получены при комнатной температуре и $77 \mathrm{~K}$ в диапазоне напряженности магнитного поля \pm 3550 Ое.

\section{3. Экспериментальные результаты}

Исследования структуры слоев методом высокоразрешающей просвечивающей электронной микроскопии 


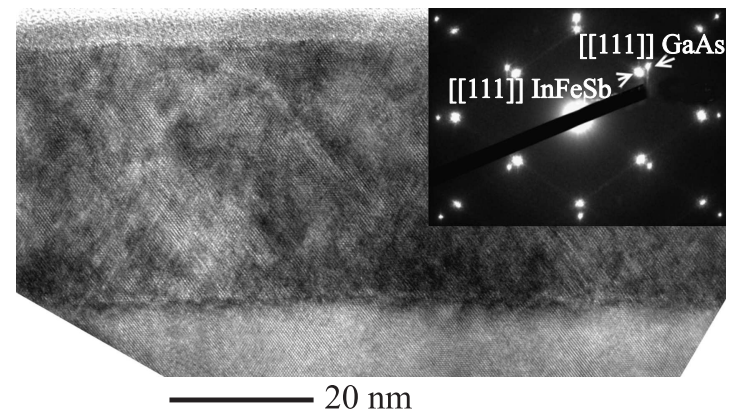

Рис. 1. ВРПЭМ-изображение структуры InFeSb/GaAs. На вставке представлена дифракционная картина от интерфейса $\mathrm{InFeSb} / \mathrm{GaAs}$.

(ВРПЭМ) показали, что слои InFeSb являются эпитаксиальными. На рис. 1 представлено ВРПЭМ изображение участка поперечного среза структуры InFeSb/GaAs, полученной при $250^{\circ} \mathrm{C}$ с технологическим содержанием железа $Y_{\mathrm{Fe}}=0.17$. Слой InFeSb является монокристаллическим, включений второй фазы в виде металлического $\mathrm{Fe}$ или соединений $\mathrm{FeSb}$ не обнаружено. Определенное рассогласование кристаллических решеток слоя $\mathrm{InFeSb}$ и подложки GaAs $\Delta a / a$ в направлении роста составляет $\approx 14.9 \%$, что совпадает с величиной $\Delta a / a$ для монокристаллических InSb и GaAs. В то же время определенная величина $\Delta a / a$ в плоскости слоя $\mathrm{InFeSb}$ составляет $\sim 10.9 \%$, следовательно, слой InFeSb coхраняет напряжения сжатия. Микродифракция от области InFeSb/GaAs, включающей подложку и эпитаксиальный слой, содержит рефлексы, соответствующие GaAs (с меньшей постоянной решетки) и InFeSb (вставка к рис. 1). Дополнительной сетки рефлексов, связанных с наличием второй кристаллической фазы, не выявлено. Исследования элементного состава структуры методом энергодисперсионной рентгеновской спектроскопии в процессе ПЭМ исследований показали равномерное распределение атомов $\mathrm{Fe}$ в слое. Исследования электронной дифракции на отражение показали, что слой $\mathrm{InFeSb}$ c $Y_{\mathrm{Fe}}=0.13$, полученный при $30^{\circ} \mathrm{C}$, является поликристаллическим. Слои InFeSb с $Y_{\mathrm{Fe}}=0.13$, полученные при температурах 150, 200 и $250^{\circ} \mathrm{C}$, являются монокристаллическими - электронограммы представляют собой сетку точечных рефлексов.

На рис. 2 представлены спектры отражения для слоев InFeSb, полученных при 30 (кривая 2), 200 (кривая 3) и $250^{\circ} \mathrm{C}$ (кривая 4). Спектр отражения для структуры $\mathrm{InSb} / \mathrm{GaAs}$, полученной при $250^{\circ} \mathrm{C}$ и не содержащей $\mathrm{Fe}$, представлен кривой 1. Спектр отражения для структуры $\mathrm{InSb} / \mathrm{GaAs}$ совпадает со спектром для монокристаллического InSb и содержит особенности, связанные с характерными межзонными переходами в пределах зоны Бриллюэна [5]. Наиболее выражены пики дублета вблизи $E_{1}(1.85$ и $2.36 \mathrm{eV})$ и интенсивный пик переходов $E_{2}$ $(4.13 \mathrm{eV})$. Для структур InFeSb/GaAs, полученных при 200 и $250^{\circ} \mathrm{C}$, хорошо разрешаются пики дублета $E_{1}$ и пик $E_{2}$. Это подтверждает высокое кристаллическое качество слоев InFeSb и показывает сохранение зонной структуры InSb. Для слоя InFeSb, полученного при $30^{\circ} \mathrm{C}$, пики дублета вблизи $E_{1}$ не разрешаются, что является следствием поликристаллической структуры слоя.

Нелегированный слой $\mathrm{InSb}$, полученный при $250^{\circ} \mathrm{C}$, демонстрирует $n$-тип проводимости при 77 и $295 \mathrm{~K}$. Для слоя InSb слоевая концентрация электронов проводимости и их подвижность при комнатной температуре составляли $1.2 \cdot 10^{12} \mathrm{~cm}^{-2}$ и $1200 \mathrm{~cm}^{2} / \mathrm{V} \cdot \mathrm{s}$ соответственно. Исследования магнитополевых зависимостей

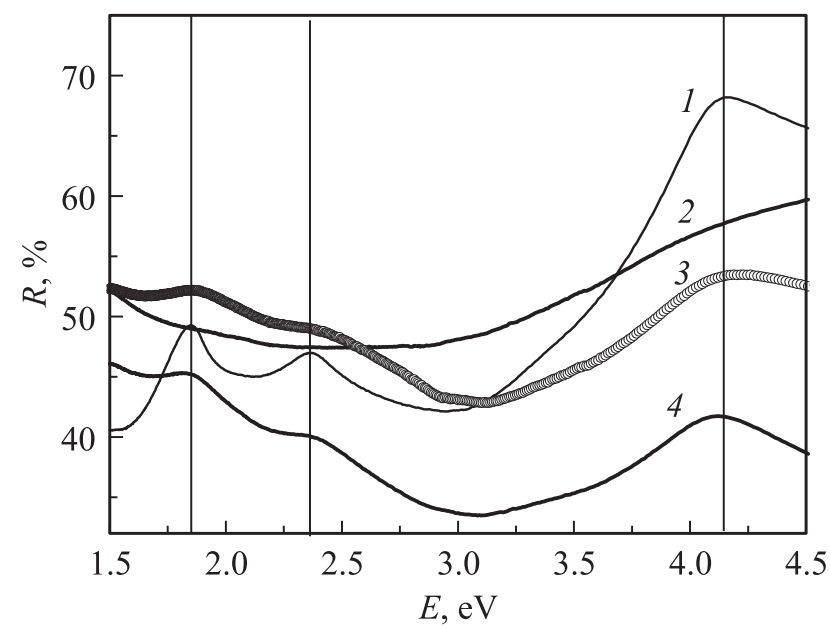

Рис. 2. Спектры отражения для структуры $\mathrm{InSb} / \mathrm{GaAs}$ (кривая 1), структур InFeSb/GaAs, полученных при 30 (кривая 2), 200 (кривая 3) и $250^{\circ} \mathrm{C}$ (кривая 4).

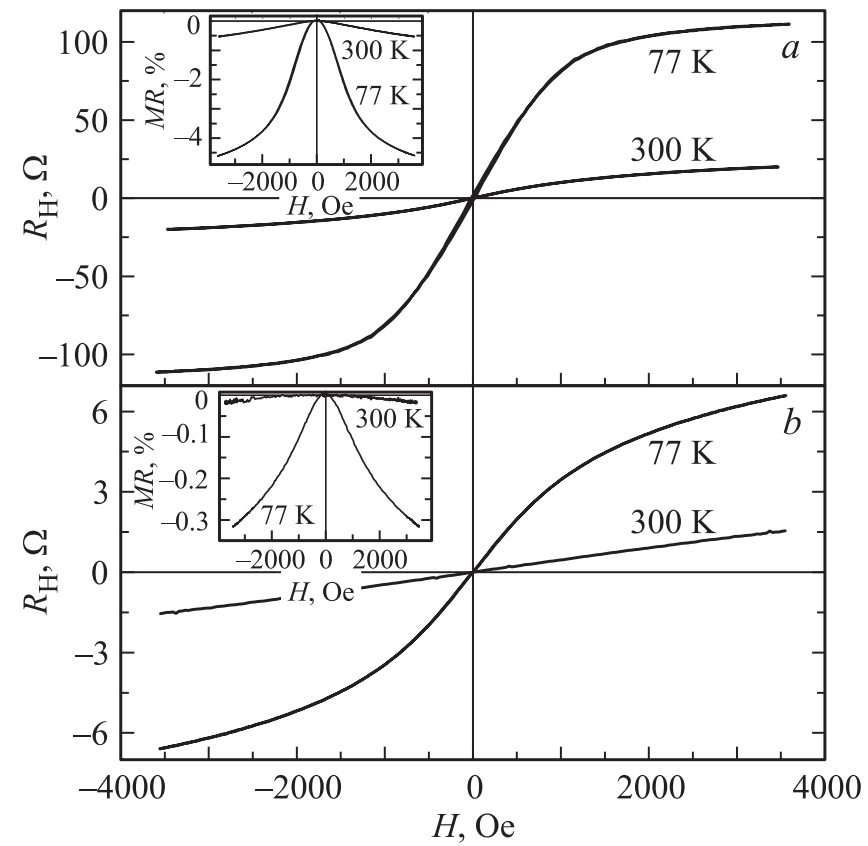

Рис. 3. Магнитополевые зависимости сопротивления Холла для слоев $\mathrm{InFeSb}$, полученных при 250 (a) и $30^{\circ} \mathrm{C}(b)$. На вставке представлены кривые магнетосопротивления. 
сопротивления Холла $R_{\mathrm{H}}(H)$ и слоевого сопротивления выявили, что слои InFeSb являются ферромагнитными, по крайней мере, до комнатной температуры. В слоях $\mathrm{InFeSb}$ наблюдается аномальный эффект Холла и отрицательное магнетосопротивление. На рис. 3 представлены зависимости сопротивления Холла от магнитного поля при 300 и $77 \mathrm{~K}$ для слоя InFeSb с $Y_{\mathrm{Fe}}=0.17$, полученного при $250^{\circ} \mathrm{C}$ (рис. $\left.3, a\right)$, и слоя InFeSb с $Y_{\mathrm{Fe}}=0.13$, полученного при $30^{\circ} \mathrm{C}$ (рис. $3, b$ ). Аномальный эффект Холла проявляется в виде ярко выраженной нелинейной зависимости $R_{\mathrm{H}}(H)$ с насыщением в магнитном поле $\sim 1500 \mathrm{Oe}$. Для слоев $\mathrm{InFeSb}$ знак сопротивления Холла соответствует $p$-типу проводимости. Проявление аномального эффекта Холла не позволяет однозначно сделать вывод о типе проводимости материала. Известно, что в магнитном полупроводниковом слое может наблюдаться одновременно аномальный и нормальный эффект Холла различных знаков, в частности, в слоях InFeAs [2], GaMnSb [6]. Имеются данные как о донорном, так и об акцепторном характере примеси Fе в матрице $\mathrm{InSb}$ [7]. Для выявления типа основных носителей в полученных слоях $\mathrm{InFeSb}$ необходимо проведение дополнительных исследований. Как нами было показано ранее, присутствие ферромагнитных включений второй фазы в полупроводниковой матрице может приводить к наблюдению нелинейных зависимостей $R_{\mathrm{H}}(H)$, не связанных с аномальным эффектом Холла [8]. Поскольку в полученных слоях InFeSb не наблюдается включений второй фазы, можно заключить, что аномальный эффект Холла и отрицательное магнетосопротивление свидетельствуют о собственном ферромагнетизме в полупроводниковой матрице и о наличии преимущественной спиновой поляризации у носителей заряда. На вставках к рис. 3 представлены зависимости магнетосопротивления при 300 и $77 \mathrm{~K}$ для случая ориентации магнитного поля перпендикулярно плоскости структур. Подобный вид зависимостей $R_{\mathrm{H}}(H)$ и магнетосопротивления наблюдался для слоев $\mathrm{GaFeSb}$ [3]. Обращает на себя внимание то, что в слое InFeSb, полученном при комнатной температуре, также наблюдаются спин-зависимые транспортные явления (рис. $3, b)$.

\section{4. Заключение}

Таким образом, методом лазерного распыления в вакууме впервые получены слои ферромагнитного полупроводника InFeSb с температурой Кюри выше комнатной. Исследования структуры InFeSb методом высокоразрешающей просвечивающей электронной микроскопии и микродифракции показали отсутствие включений второй фазы со структурой, отличной от структуры матрицы InSb. Ферромагнитные свойства слоев проявляются в особенностях транспорта носителей заряда, что открывает возможность использования полученных полупроводниковых слоев для создания приборов, использующих спин-зависимые эффекты.

\section{Список литературы}

[1] M. Tanaka, S. Ohya, P.N. Hai. Appl. Phys. Rev. 1, 011102 (2014).

[2] А.В. Кудрин, Ю.А. Данилов, В.П. Лесников, Е.А. Питиримова. ПЖТФ 42, 63 (2016).

[3] N.T. Tu, P.N. Hai, L.D. Anh, M. Tanaka. Appl. Phys. Lett. 108, 192401 (2016).

[4] L.D. Anh, D. Kaneko, P.N. Hai, M. Tanaka. Appl. Phys. Lett. 107, 232405 (2015).

[5] R.R.L. Zucca, Y.R. Shen. Phys. Rev. B 1, 2668 (1970).

[6] X. Chen, M. Na, M. Cheon, S. Wang, H. Luo, B.D. Mc Combe, X. Liu, Y. Sasaki, T. Wojtowicz, J.K. Furdyna, S.J. Potashnik, P. Schiffer. J. Appl. Phys. 103, 043701 (2008).

[7] Э.М. Омельяновский, В.И. Фистуль. Примеси переходных металлов в полупроводниках. Металлургия, М. (1983). C. 159.

[8] A.V. Kudrin, A.V. Shvetsov, Yu.A. Danilov, A.A. Timopheev, D.A. Pavlov, A.I. Bobrov, N.V. Malekhonova, N.A. Sobolev. Phys. Rev. B 90, 024415 (2014). 